\title{
Improving Supply Chain Management of a Distribution firm using ERP System
}

\author{
Khan U., Asim M., and Manzoor S.
}

\begin{abstract}
This research deals with how the Supply Chain Management of a Distribution company can be improve by using the ERP System. Efficient Supply chain management has prominent role in placing the company at competitive advantage \& enhances the productivity of firm. Supply chain management is the strategy which aims for decreasing the costs \& enhancing the customer satisfaction. ERP is considered to be Productive instrument for the company which fits as per the need of consumer \& distributors. ERP provide the quality system, user satisfaction and system usage. It helps in better planning; decision making and increases the overall performance of the organizational performance. Efficient time management is also provided by ERP.
\end{abstract}

Keywords - Information Technology; Supply Chain Management; ERP System

\section{INTRODUCTION}

The supply chain management is a highly efficient strategy for sustaining the competitive advantage and the productivity of firm [16][21]. For obtaining a good competitive position, the supply chain management is an approach which purposes for reducing the costs as well as providing the good linking of production as well as distribution systems and for enhancing the customer satisfaction [1][26][35]. The supply chain management is a procedure for controlling the data flow, products (property) as well as services in-between and within the organizations and also makes the firm ties among the consumers and suppliers. In accordance with the Mzoughi and the other (2008), the supply chain management articles depends upon the strategic management, logistics, strategies, partnerships as well as marketing [3][21]. The comprehension of HR management expands to all distribution as well as transporting services which acquire the whole logistics phenomena and increases the supply unit. Supply chain management refers to contain all systems of the organizations developed raw materials as well as resources till the last stage [18][25]. If whole strategic firms work like an only united object, then the performance of the supplier's system will always be enhanced or improved. The supply chain management success as well as the information technology (IT) advancements needs ERP systems combination [28]. It will give competitive advantage and will be enabling sales managers for meeting customer's expectations. ERP systems are achieved by all sizes of companies or organizations [30][31].

The system of ERP (Enterprise Resource Planning) is a basic instrument for the planning of the business strategies, information transmitting, execution of them as well as controlling of them, associated with organization's resources which include material resources, financial resources, tools and employees, that are organized premises within various areas [19][33]. The actions and practices of supply chain

Published on March 10, 2020. management attained by the organizations as an extroverted door for ensuring mutual benefits within their own procedures [5][20][35]. Successful implementation and integration of ERP system and the supply chain management actions give benefits in process of decisionmaking, planning, execution as well as enhances the organizational performance [24].

Many researchers examine the association among the practices of supply chain management and organizational performance through the usage of ERP systems $[28][34][35]$. For increasing the flexibility as well as the proficiency of organization, it requires for implementing the strategies of supply chain management [2][3][20]. The actions related to supply chain management have a great influence upon the performance of organization and the competitive advantage of organization [21]. The ERP system as well as Supply Chain Management works as efficient tools for the enhancement of organizational performance and give a continuing competitive advantage. The ERP Systems deals with the improvement within operations of work and the effective usage of information $[4][22][33]$. It is the technology which influences the information system, workflow as well as the interaction influence among the organization employees. Organizations have few marketing as well as financial aims [24][33]. Then trying for reaching these aims. Moreover, the organizations may approach the competitive advantage through development of strategic association orientation of shared achievements, developing the associations with restricted limit of suppliers.

The main aim of the study is to analyze the improvement in supply chain management of a distribution firm using ERP system [4][25]. The purpose of the research is for evaluating the ERP system used by companies for improving the supply chain management. In this research, the four aspect of the ERP systems have been evaluated which are useful for improving the supply chain management including automation, record keeping, time management and artificial intelligence use.

\section{A. Research Question}

How the improvement of supply chain management of a distribution firm is achieved by using ERP system?

The rationale of the research includes the purpose of doing this research. The rationale of the research is that the ERP systems have been useful for getting the competitive advantage and improved supply chain management for increasing the organizational performance [26][35]. The SCM actions are abstracted in terms of four-dimensional building. A number of organizations which are welldeveloped, have been utilizing the ERP systems for improving the supply chain management of the distribution 
firm [29][36]. Many researchers examine the association among the practices of supply chain management and organizational activities with the help of ERP systems. For increasing the flexibility as well as the proficiency of organization, it requires for implementing the strategies of supply chain management [20][36]. The actions related to supply chain management have a great influence upon the performance of organization and the competitive advantage of organization.

The ERP system as well as Supply Chain Management works as efficient tools for the enhancement of organizational performance and give a continuing competitive advantage [9]. The ERP Systems deals with the improvement within operations of work and the effective usage of information. It is the technology which influences the information system, workflow as well as the interaction influence among the organization employees [8]. Various researches have been conducted for the evaluation of ERP systems usage by the organizations for acquiring the competitive advantage and increasing the organizational performance whereas this research will provide the information about the ERP systems used by the firms which directly impact on their supply chain management [20]. As all of these are interrelated with each other, improving of supply chain practices will led to the improvement of firm's competitive advantage by the cost eminence, services consistency, updated marketing as well as innovation in the market's products [19]. Previous studies have showed the multiple SMC actions including the strategic supplier partnership have a great influence on the different aspects of competitive advantage [12]. This research will show that the ERP systems can be valuable for improvement of supply chain management.

\section{B. Research Hypotheses}

- H1: Supply chain operations of a Distribution is improved by ERP system due to its Automation

- H2: Supply chain operations of a Distribution is improved by ERP system due to its Record keeping

- H3: Supply chain operations of a Distribution is improved by ERP system due to its Time management

- H4: Supply chain operations of a Distribution is improved by ERP system due to its Artificial Intelligence

\section{LITERATURE REVIEW}

The study includes the vast range of literature including articles, researches, books, journals and internet-based researches for the explanation, in addition, evidencing of the current research as it delivers the indication and explanation for the research question [9]. The literature consists of the terms and their explanations including Supply chain management, ERP systems and the organizational performance and competitive advantage [10].

The company use supplier's processes by the way of logistics chain management in order to enhance its advantage. The consumer and provider are the external logistic part of the corporation [11]. The matter and the knowledge flows through the logistic chain is related by SCM. It focuses mainly on the external environment. Thus, in the modern era of business management and working environment the SCM focuses on the internal part too [12][36]. It is impossible to gain success without considering the realities of global market supply chain. By not implementing an advanced technology it is impossible to achieve whole success only by combining the designs, dispense, and manufacture processes and the managerial aspects [13]. The main factor of the success lies in the way to cover this form of management by executing supply chain network. SCM execution were defined in various research activities as consumer relationship, distributor partnership, foreign procurement and sharing various information and technologies etc. [14] Their work has been set up on the five main basic and important activities that are, consumer relationship, and strategies of the distributer, sharing of various knowledge and information, delay and quality levels. The consumer relationship and the distributor strategies, quality levels, sharing of simplest knowledge and information, social sciences are applications of SCM which provide prominent benefit to various associations [14].

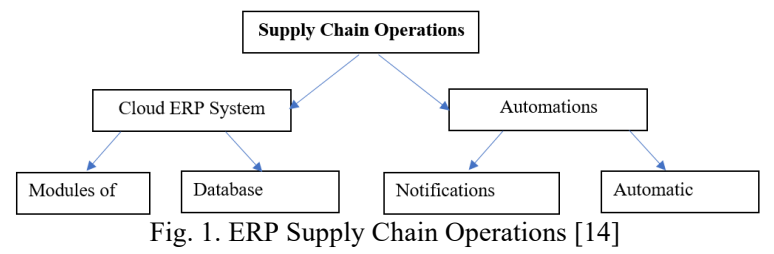

The presentation of the distributor has a prominent impression upon the quality of product, cost of the product, delivery time, technology, alteration and manufacturing of the firm also affects the challenges and benefit of the organization [23]. By doing the strategic partnership of the main distributors, the quality of the resources utilized can also be enhanced. For ensuring the quality of the product, the expansion of the organizing capacity is reliant upon the longstanding collaboration, and association of the quality of the goods and selection of the distributer. According to the desire of the partners, strategic partnership can be changed as they do not have a special form [19][37]. The election and development of the distributor's activities enhance the communication between the organizations that will lead to enhancement in the mutual trust, development and sharing of the information, adds long term partnership, develop a uniform partnership and explain strategic orientations for the partner's intention [6].

An organization is able to know the desire of the distributer and the way of developing communication in an institution when the longstanding relationship diminishes [6]. The distributors should be attentive of the consumer systems and methods to accommodate them into their activities [7][38]. Through the determination of the category as well as the stock type which assumes the partnership with distributor is established. The transaction cost is reduced by the partnership and provide benefit to the distributor as well as allow transfer of the technology. For SCM practices, consumer relationship management (CRM) is a necessary element [8]. It adds all the associations in management practices as establishment of longstanding relationship, as 
well as establishing consumer needs fulfilment is necessary to achieve. Organizations nominate suitable distributors for each consumer need in order to assure the satisfaction of the consumer [9]. Companies enhance its activities through the process of elimination of the impractical information period of the chain level, enhancing the procedure of product and IT as well as developing effective communication and relationship with applicants by means of having access to the information about the consumer's database [10].

Assistance between distributors and consumers allows organizations for achieving current news regarding appeal as well as consumer need [11]. Between distributors and consumers, the concept of traditional relationship management patterns has been completed. Hence, awareness of the agenda of the consumer's relationship and association is important [12][40].

Information conversation competence within a partnership is explained through the process of sharing information as well as the standards of information. Within the establishment of the efficacious partnership by the distributors, the elements such as sharing of information and standards of information are decisive. Sharing in knowledge between participants means describing of the analytical information and industrial estate [13]. For enhancing and establishing a number of fundamentals in the SCM for example, cost and quality of products, the distributors and consumers can collaborate. Accuracy, time, modicum, and integrity of the information is related with the quality information. The supply and demand uncertainty can be reduced by all the fundamentals regarding supply chain with the help of sharing information [12][31][32]. The sharing of information must be accurate for achieving the highest management outcomes in the SCM, also the assuring of a specific guarantee standard regarding the flexibility. Mutual exchange of information influences upon the sharing of information, the period gained for it and partnership getting advantages through the acquired information [15]. The sharing of information, time, and the participants who will take advantage from this information, these factors depends on the effects of mutual exchange of information. These strategic resources must be considered by the company as well as the providence of the notification through lessening prolonging and splitting [17][41].

Vast information can be achieved through adding the resources of organization for establishing collaborations within business partners, and meeting the needs and demands of the buyers and increases social and behavioural sciences performance's and operations is the main purpose of ERP. The solutions that are added to the business processes and firm functions can be defined by ERP system which is a standard adaptable software [22]. It is a system of information that supervise planning of the production, supplies, production, selling, distributing, accounting, consumer services by combining them all together [25][38]. A firm and global management information system that combine all the business functions is a definition of ERP system. The different department's information system is better integrated when dealt with an ERP system. The information which links supplier's group, distributers as well as consumers having no restriction about geography is enabled by the ERP system. Through the relevant and exact practice, the customer data and distributors data sharing must be instant [27]. The apparent compensations of ERP are dissimilar and problematic for being explained due to the reason that an ERP system that are implemented varies among the companies which can be tangible or intangible [20][25]. There are several advantages of an ERP system, that consists of standardization of the organizational methods, incorporation of the amenities and facts, mechanization of the exchanging procedures, enhancing the elasticity, decreasing the number of employees, building up the system of universalization as well as finding a solution to a problem. ERP system provides a competitive advantage to a logistic chain by integrating the information system [21].

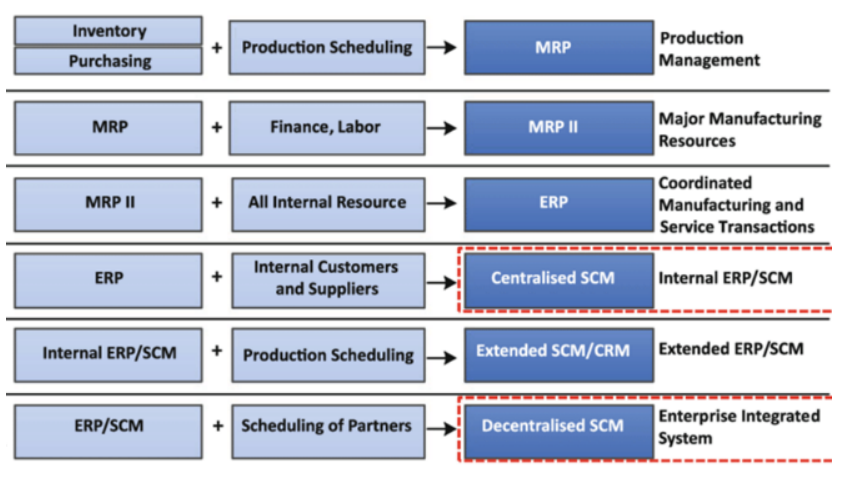

Fig. 2. ERP System and SCM Practices

The organizational performances and ongoing competitive benefit are the basis for SCM practices and ERP systems. Productive tools for institution that assist to meet the need of distributors and consumers and competitors are provided by an ERP system [20][39][40]. The quality of the system, the quality information, usage of the system, satisfaction of the user, effective individual and impact of the organization, all the factors that have the influence on the success of the ERP system [23]. The main and the important factors that have influence of an ERP success have determined the quality information, quality systems, impact of an organization, individual effects and the institutional system [24]. Through the claiming of others about the service quality, is necessary for achieving the better quality of system. The excellence includes the major system eminence is the service that is claimed by the others. Hence, some people defined service eminence in a way of recent as well as different standard, level of the representations [27]. The users of the system then evaluate the consumer's needs and when the user is absent, the support get lowers the salaries and it leads to the failure in providing quality services which is provided through the department where data is processed, in that case the external services givers plays a major role for not losing the customers [29][39]. 


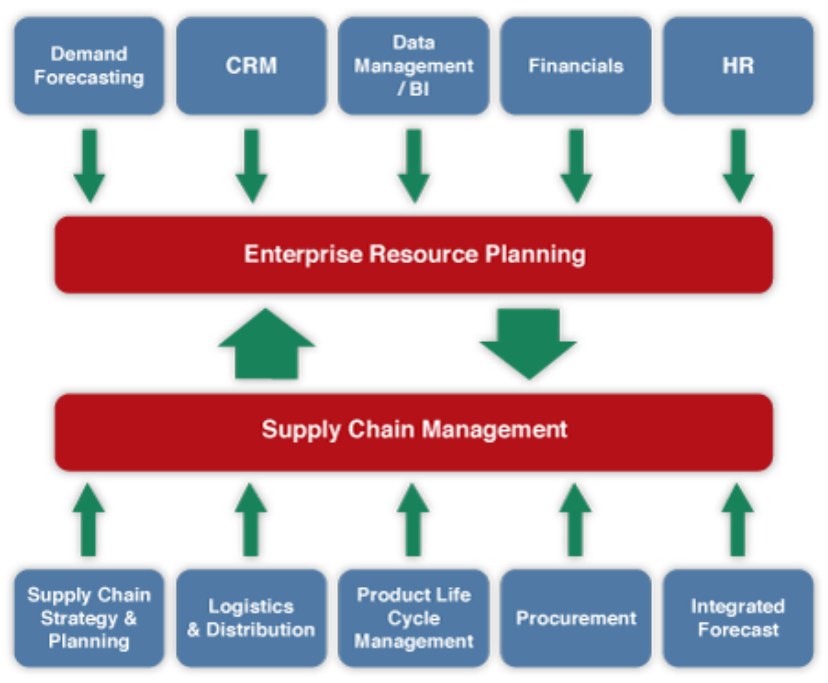

Fig. 3. ERP and SCM Relationship

Other researchers enlarge the determined criteria. For example, the achievement of the ERP system as well as prolonged connotation of the distributer and organization is directly affected during the implementation of an ERP correct software's and vendors or selection of the consultant [30]. The vendors of an ERP system and the advisor aiding in providing standard to the application which will provide the guarantee to the customers, and will be notifying the users as well. However, system quality is affected by the selection of the right system, and service quality is affected by the accurate vendor of software choosing and the influences upon consultants as well [21]. Individual impression and impact of an organization are not related in the circumferences of an ERP system.

Although the association is very linear which involves the activity related to the impression on customers as well as impression upon organization within the teamworking process (which is defined as organizational sub units or departments that are functional) [26][33][35]. Within the period of variations, the business management which is very efficient, works on the process of socio-economic risk management. Within the process of risk-depletion, protection of moral as well as business information along with the amenities have a great importance [20]. Consequently, for the assessment of the quality of the operations regarding the risk management as well as security management influencers have a large importance. It has been investigated that the influence of the internal (team of organization of project management) as well as the external influencers (vendors along with the application advisors) are on the quality of the services [21]. To reach to the success in ERP system, there are three main factors which are, vendors of the system, implementation adviser and team of firm management project. ERP implementations are infrequently successful in the organizations without the external assistance (application advisor and vendors) [21]. The probability of failure in the resolution of Social and Behavioural Sciences debate, representing the correct frame for the variations, defining the project management group aims along with the procedure of a modification can be decreased by the ERP implementations [27]. The ERP system consists of the features including automation, record keeping, time management as well as artificial intelligence which provide improvement to the supply chain management of a distribution organization [29].

\section{Methodology}

This chapter includes the methodology used by the researcher for the evaluation of the research problem which is basically the improvement of supply chain management of a distribution firm using ERP systems for which a firm is selected to evaluate the statement of the research and for getting the answers of the research questions.

The research design which is used in this research is the quantitative approach which is done through the survey by collecting data through providing questionnaires to the sample of the research. The 40 participants of both genders' males and females, were selected for conducting the survey. The findings will be analyzed through the quantitative analysis and then the collected data will be analyzed through SPSS. The study starts with the linking of the variables. The quantitative approach represents results by the numerical calculations rather than the theoretical data [14]. Therefore, the primary research will be carried out via semi-structured interview questionnaires. The survey will aid in demonstrating an aiming outcome of the study. It will be helping in generating a proper result analysis for the research statement [25][41]. The approach utilized in this research is inductive approach which is basically concerned to the starting of a new theory which generated through the data collected and the objective is for initiating a new theory depending upon the data.

The research examination is done through the participation of 40 employees of different distribution firms including the service industry and production/manufacturing industry which provided the details of the ERP systems used by them for the improvement of supply chain management [25][29]. The quantitative analysis needs the model for developing the conceptual model for clarifying the perceptive areas of the research. It includes the analysis of data collected involving the utilization of the essential information. The dependent variable of the research is the supply chain management and the independent variable of the research is ERP system (automation, record keeping, time management and artificial intelligence). The surveys will be acquired through supporting a proper response depends upon and considering the ethical considerations.

While the research is in process, the attention was given to the ethics which is necessary for the standards and ethical considerations strengthening and the research quality along with the authenticity of the research [30]. The ethical adhere the validity and reliability of the research in terms of the authentic surges of research [12]. Therefore, prior access to the online as well as offline capitals, the recommendation involves the achievement of proper guidelines by the concerned personnel for accomplishing the requirement of research work as well as the researcher cannot be the patent victim in terms of breaching the rules [28]. Above and beyond, the surveys as well as interviews are needed for taking the part in study, for which the duty of researcher is greatly for ensuring the privacy by concentrating upon the assiduousness due to which the participants will highly cooperate with the researcher and will be willing for giving 
the researcher the authentic information. Therefore, the ethics is the major thing to achieve which diminishes biases in the research very efficiently [24].

\section{ANALYSIS}

\section{A. Analysis}

The findings and analysis of the research include the answers of the research question as well as the evidences for the hypotheses of research. The findings included the graphs and charts for the evaluation of the interpretation of the results which are also included in this chapter. The demographic information of the participants is given below along with the interpretations.

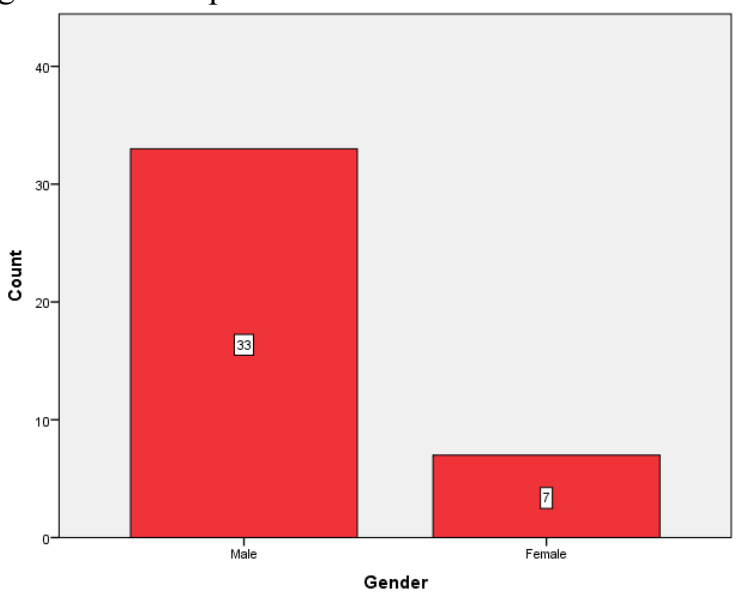

As per the statistics of this research, majority were the males who participated in this research.

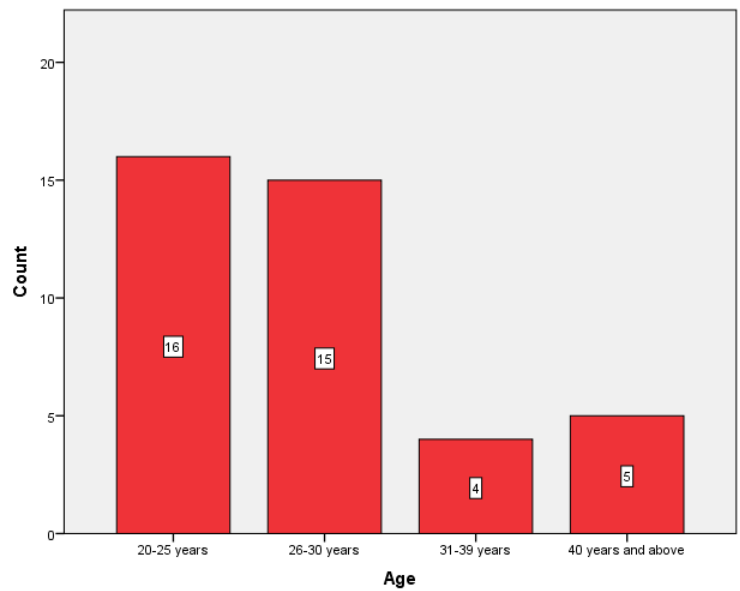

The age groups participated in the research were all 20$25,26-30,31-39$ and 40 and above but the majority of the participants were from age group 20-25 which was a youth working in the firms.

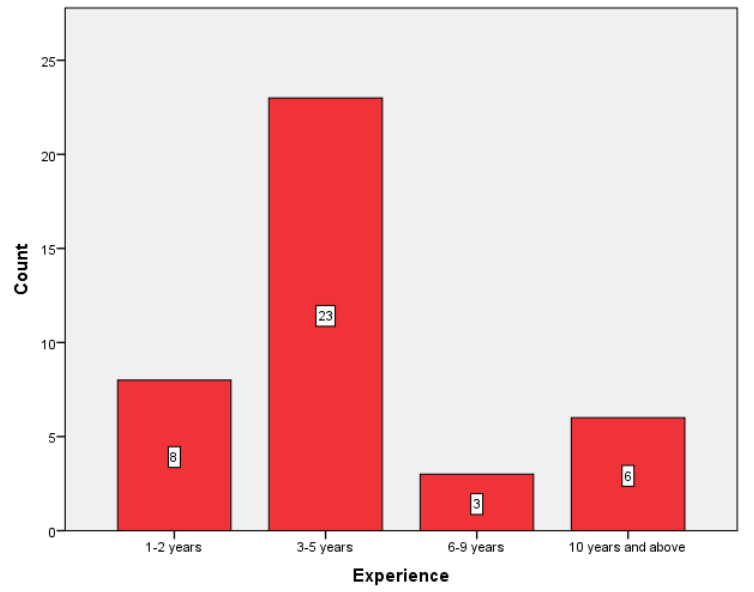

The most of the participants which were 23 participants were having the experience of 3-5 years which have an enough knowledge regarding the ERP systems and Supply chain management along with the other systems of the organizations.

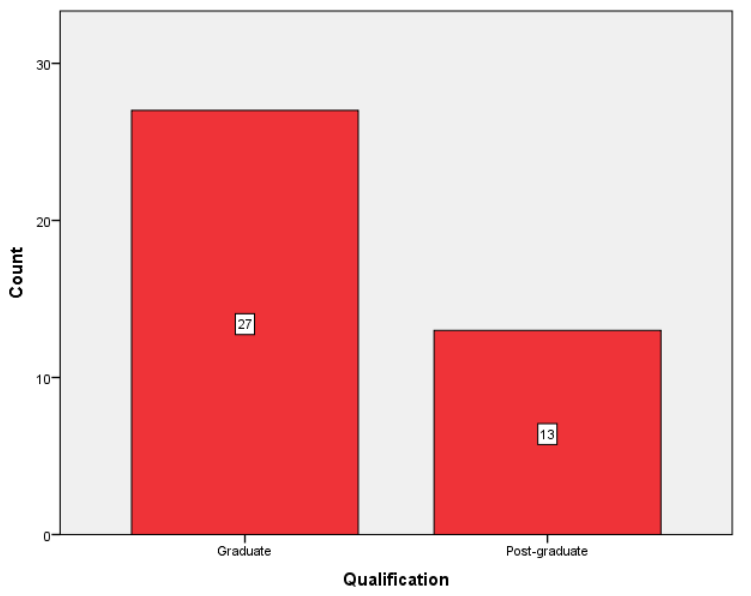

Majority of the participants that were 27 participants were only graduated and other 13 were post-graduated.

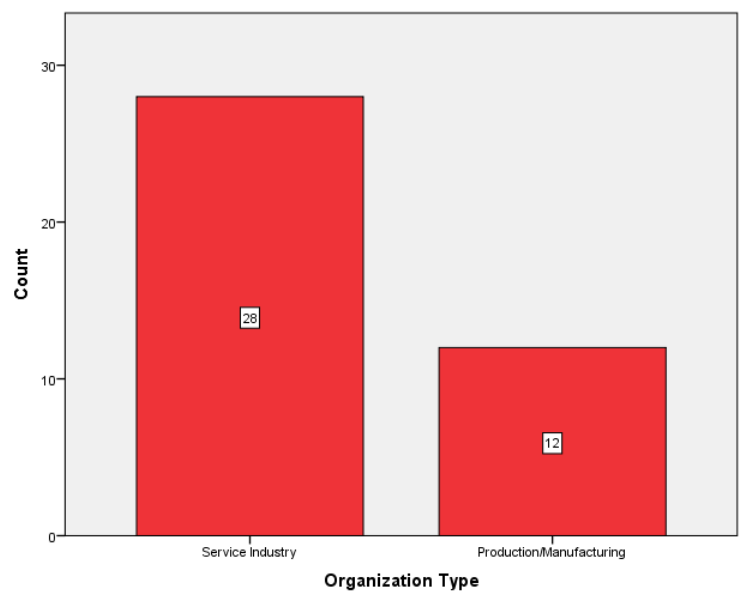

The most of the employees were working in service industry who participated in the research. 


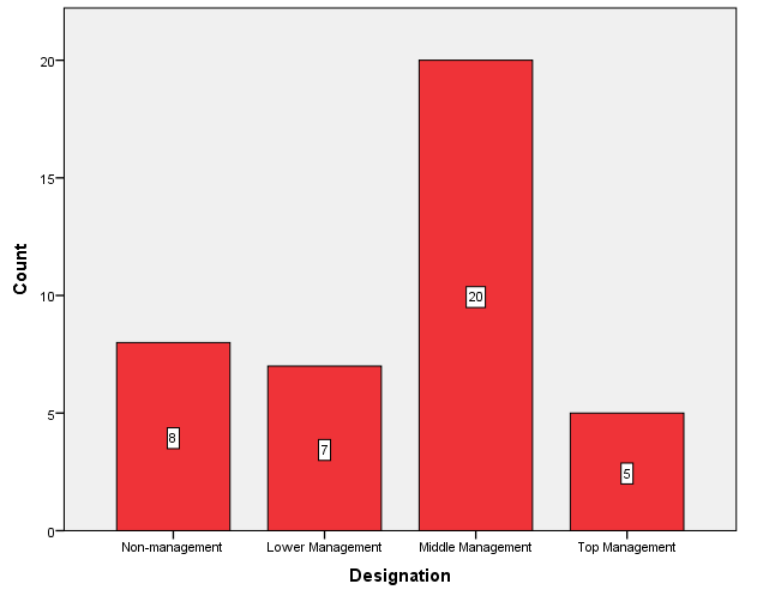

Most of the participants were in middle management that were 20 participants who were working in middle management, 8 were in non-management, 7 were in lower management and 5 were in top management.

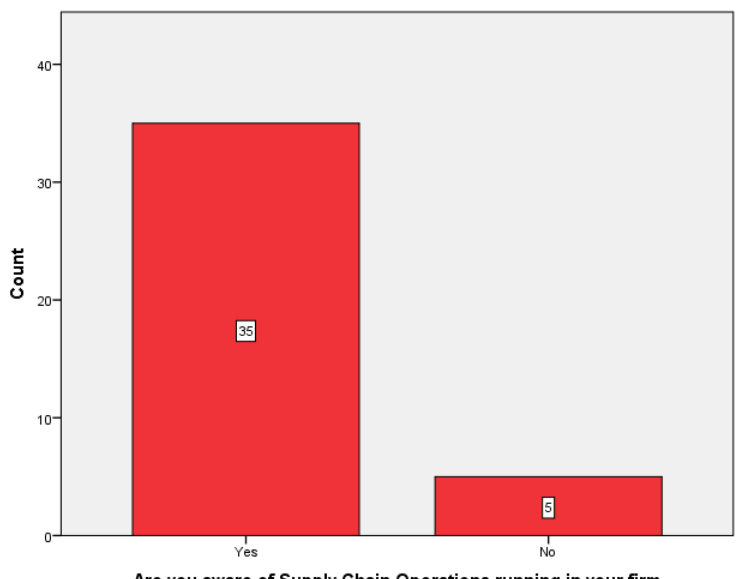

Most of the participants were aware of the supply chain operations running in their firms. 35 participants were aware of the supply chain operations running in their firms and other 5 participants were not aware.

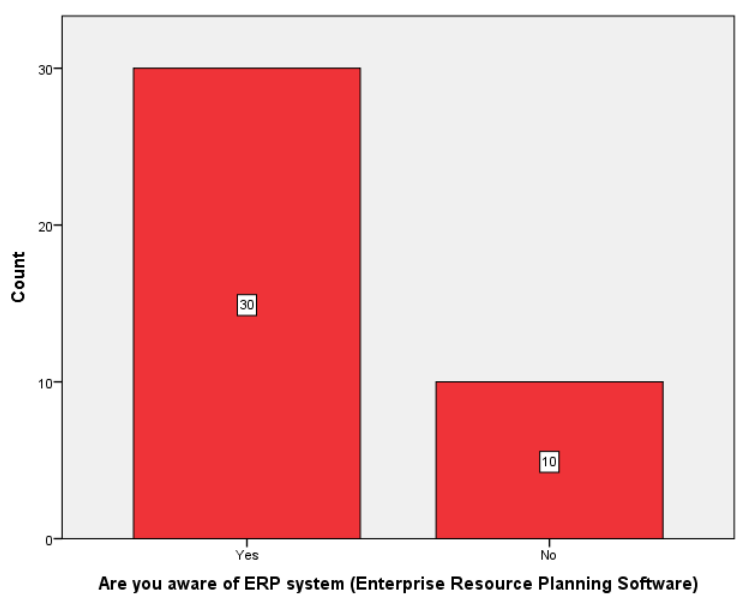

Most of the participants were aware of the enterprise resource planning system in their firms. 30 participants were aware of the ERP running in their firms and other 10 participants were not aware.

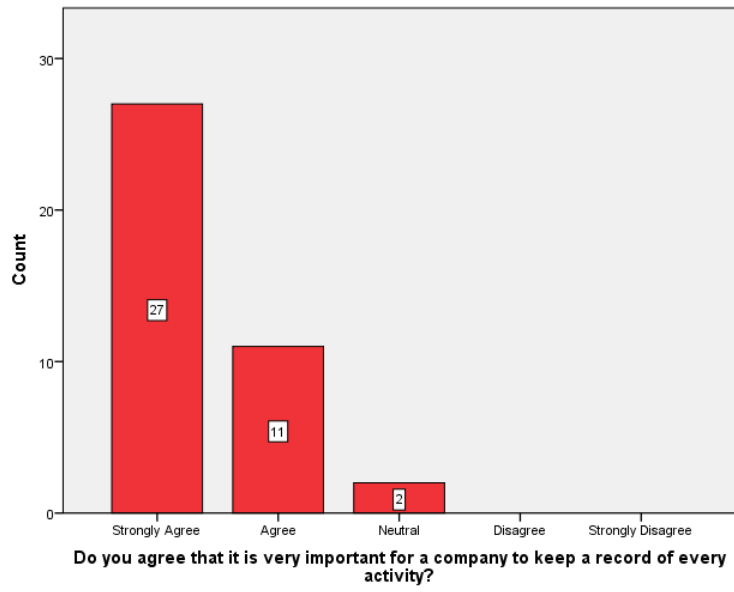

Most of the participants (i.e. 27 workers) were strongly agreed on the statement which means that the record keeping is very important for the company. Other 11 participants were agreed on the statement and 2 participants were neutral.

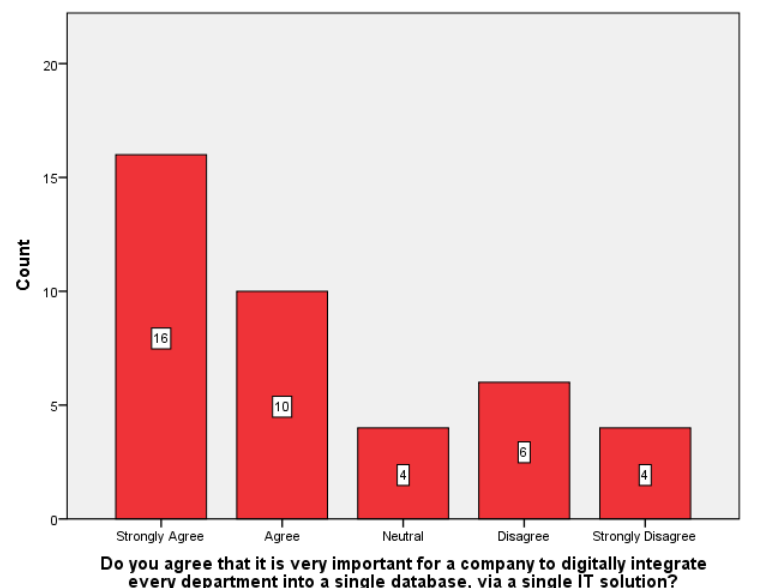

Most of the participants (i.e. 16 participants) were strongly agreed on the statement that the digital database usage is done as the single IT solution. 10 participants were only agreed, 4 have neutral response over it and other 10 were disagree and strongly disagreed with the statement.

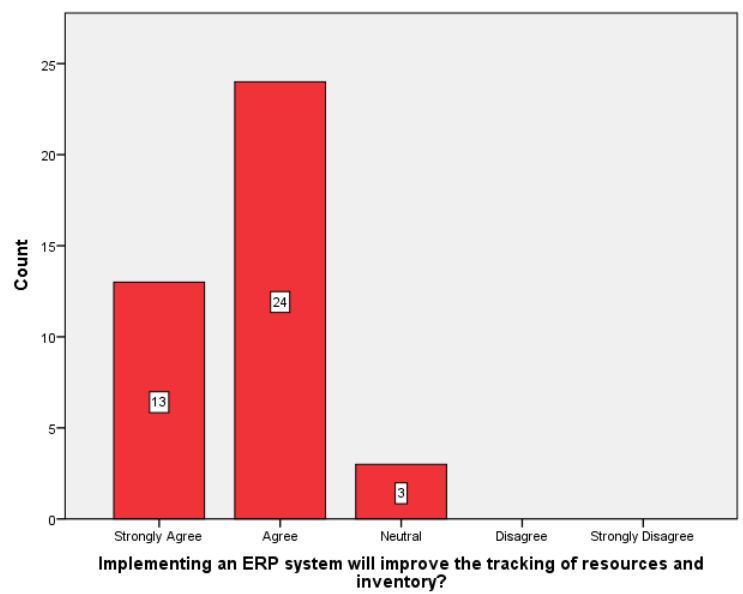

Most of the participants (i.e. 24 participants) were agreed on the statement that the ERP system will improve the tracking of resources and inventory. 13 participants were strongly agreed and other 3 participants were neutral. 


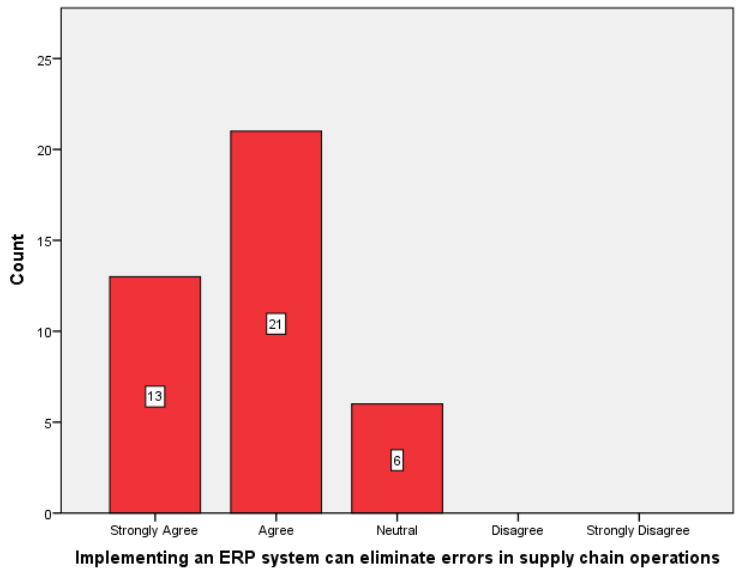

Most of the participants (i.e. 21) were agreed upon the statement that ERP systems eliminates the errors in Supply chain management operations. 13 participants were strongly agreed and other 6 were neutral.

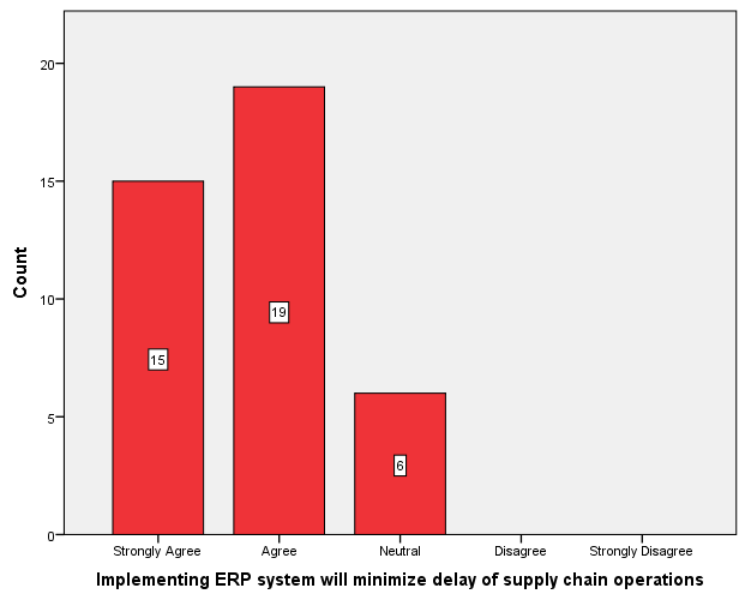

19 participants were agreed on the statement that implementing ERP systems minimizes the delay in supply chain management operations. 15 participants were strongly agreed with the statement and 6 were neutral.

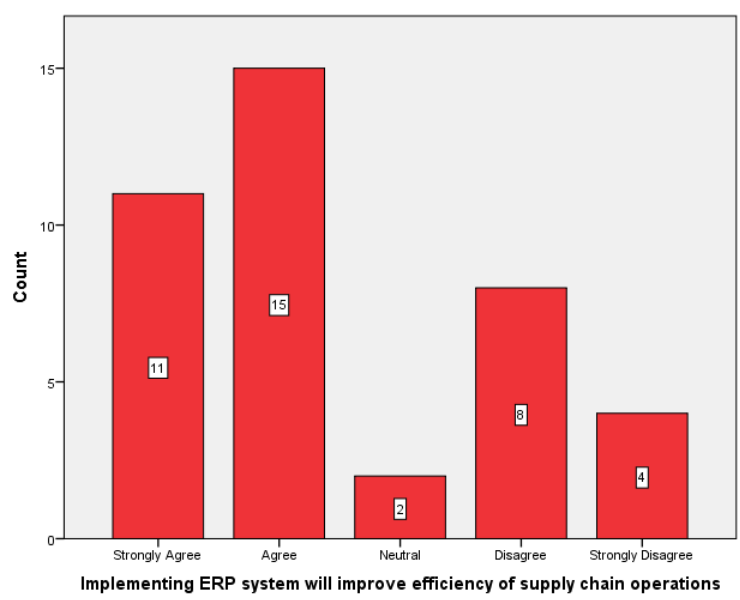

15 participants were agreed upon the statement that ERP system improves the efficiency of supply chain operations 11 participants were strongly agreed on the statement, 2 participants were neutral, 8 were disagreed with the statement and other 4 were strongly disagreed on the statement.

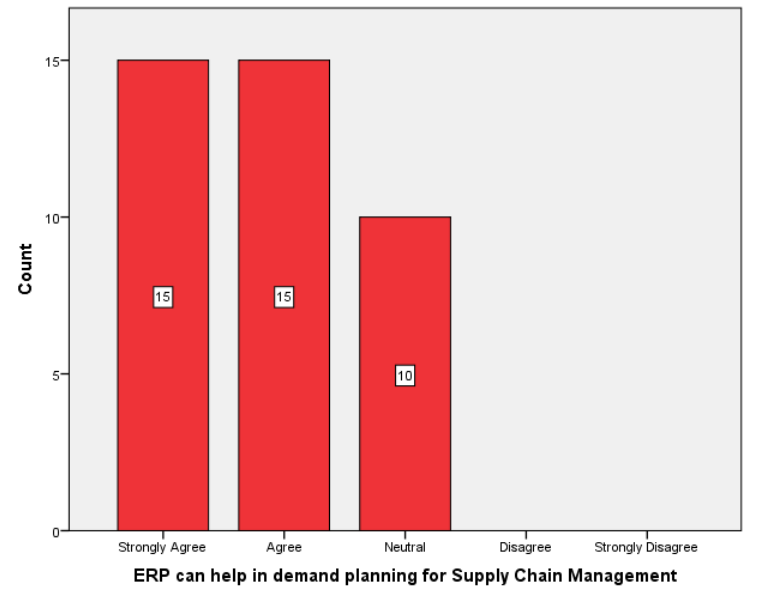

Most of the participants that is 30 participants were strongly agreed and agreed upon the statement that ERP can aid in demand planning for supply chain management. Other 10 were neutral about the statement.

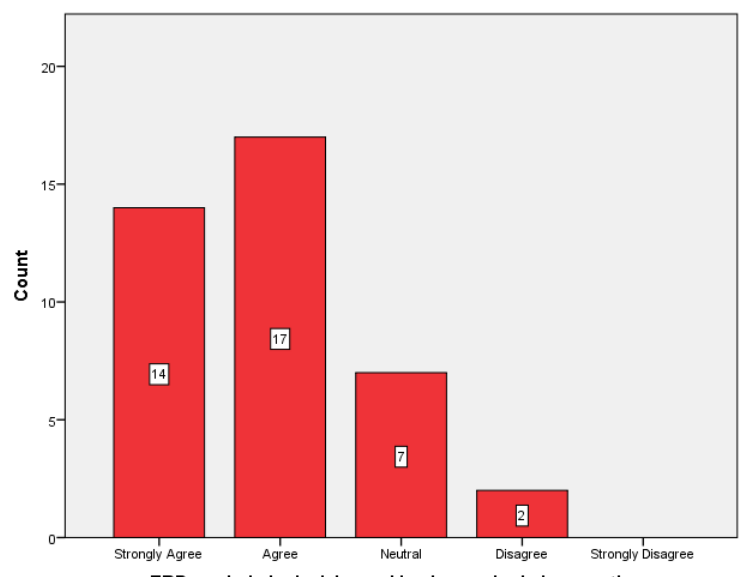

Most of the participants that are 17 participants were agreed upon the statement that ERP can aid in decision making in supply chain management. 14 participants were strongly agreed with the statement, 7 had neutral response and other 2 were disagreed from the statement.

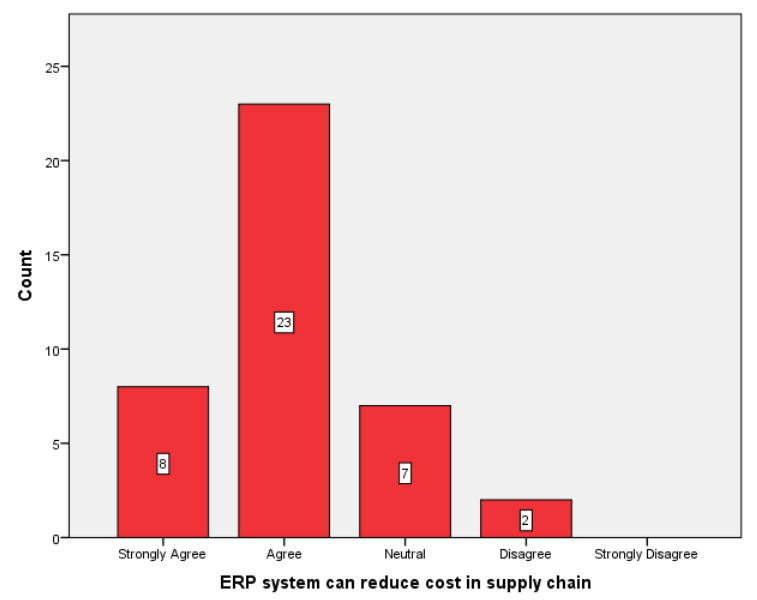

Most of the participants (i.e. 23 people) are agreed with the statement that ERP systems reduces the cost of supply chain management. 8 participants were strongly agreed with the statement, 7 participants were neural and other 2 were disagreed with the statement. 


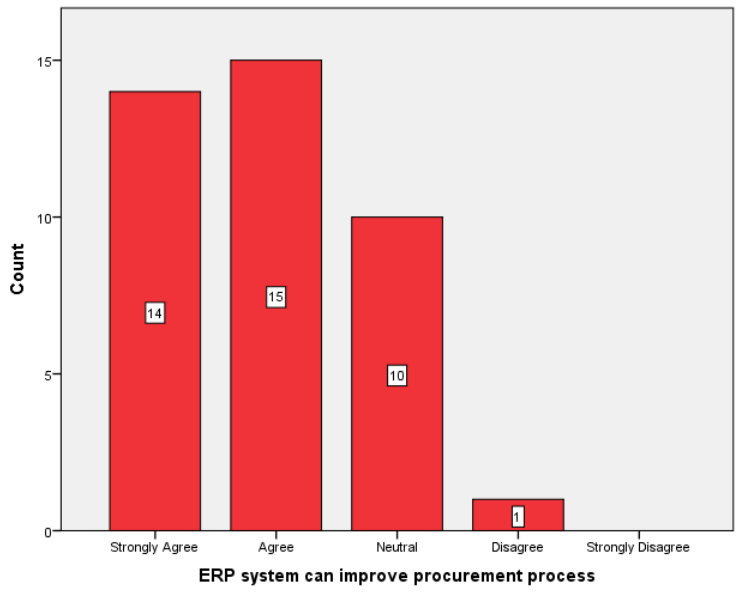

Most of the participants (i.e. 15 participants) were agreed upon the statement that the ERP system improves the procurement process, 14 participants were strongly agreed on the statement, 10 were neutral and 1 was disagreed with the statement.

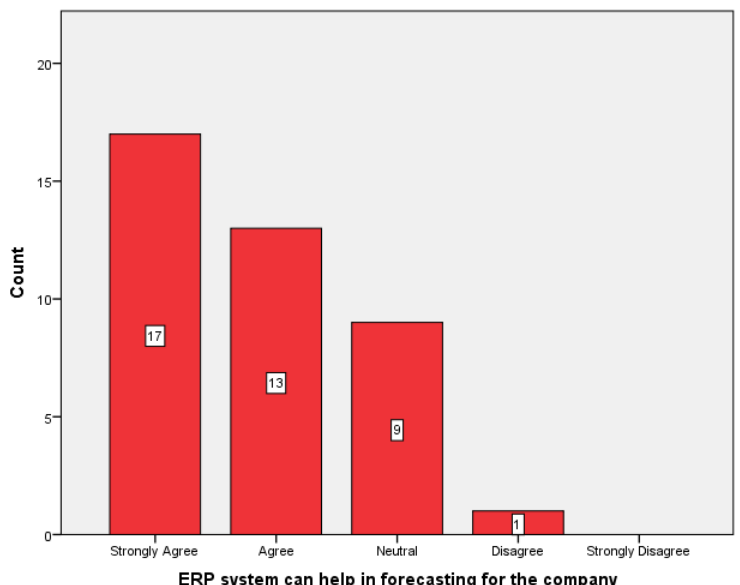

Most of the participants were strongly agreed by the statement that ERP system aids in forecasting of the organization. 13 participants were agreed by the statement, 9 had neutral response, other 1 was disagreed with the statement.

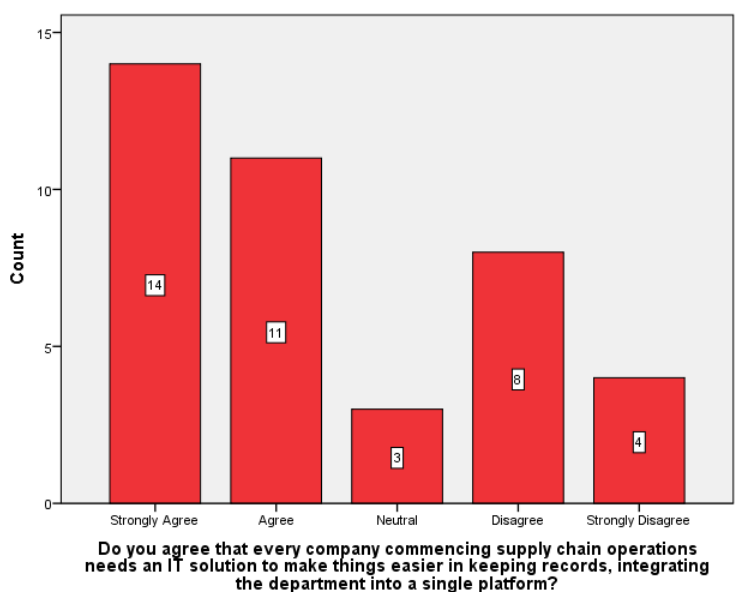

Most of the participants were agreed upon the statement that every organization commencing SCM practices requires an IT solution for making things easier in keeping records, integrating the department into a single platform. 11 participants were agreed from the statement, 3 were neutral, 8 were disagreed and other 4 were strongly disagreed with the statement.

All of these findings have their own clear interpretations which are described through charts which are following that are showing that the hypotheses of this research have been proved.

\section{DiscusSION}

This chapter includes the discussion of the interpretations of the findings and the conclusion based on the findings are given. The research question of the research included How the improvement of supply chain management of a distribution firm is achieved by using ERP system. Although the research hypotheses were 1) Supply chain operations of a Distribution is improved by ERP system due to its Automation, 2) Supply chain operations of a Distribution is improved by ERP system due to its Record keeping, 3) Supply chain operations of a Distribution is improved by ERP system due to its Time management, 4) Supply chain operations of a Distribution is improved by ERP system due to its Artificial Intelligence.

The findings achieved were explaining and answering the research question very accurately and prominently that includes the improvement of Supply chain management practices (automation, record keeping, time management and use of artificial intelligence) through the use of ERP system [12]. Findings concluded that ERP systems eliminates the errors in Supply chain management operations very prominently. Similarly, the literature explained that the organizational performances and ongoing competitive benefit are the basis for SCM practices and ERP systems. Productive tools for institution that assist to meet the need of distributors and consumers and competitors are provided by an ERP system [13]. Literature also included that the ERP system can enhance the practices of the SCM because of its automation. Findings further included that implementing ERP systems minimizes the delay in supply chain management operations which is also evidenced by the literature that successful implementation and integration of ERP system and the supply chain management actions give benefits in process of decision-making, planning, execution as well as enhances the organizational performance [10]. Findings concluded that ERP system further improves the efficiency, demand planning and decision-making of the SCM operations. Moreover, literature and findings both concluded that the ERP can reduce the delays in SCM operations including the improvement of efficiency, reduction in cost of SCM, improves the procurement process, aids in forecasting of the organization [7]. This is also concluded through the research that every organization commencing SCM practices requires an IT solution for making things easier in keeping records, integrating the department into a single platform.

\section{CONCLUSION}

The research findings concluded the linear connection between the activity of the customer impression as well as administrative impression within the teamworking (which is defined as organizational sub units or departments that are 
functional). The quality of the system, the quality information, usage of the system, satisfaction of the user, effective individual and impact of the organization, all the factors that have the influence on the success of the ERP system [23]. The main and the important factors attained by the findings of the research that have influence of an ERP success have determined the quality information, quality systems, impact of an organization, individual effects and the institutional system [24].

\section{REFERENCES}

[1] Abro, M.M.Q., Memon, Z.A., Shah, A.A. and Naqvi, I.B., "Antecedents of Enterprise Resource Planning and its Impact on Firm Perfromance with Supply Chain Integration as Mediating factor" Mehran University Research Journal of Engineering and Technology 36(2), pp.407-418, year 2017.

[2] Apiyo, R. and Kiarie, D., "Role of ICT tools in supply chain performance" International Journal of Supply Chain Management, 3(1), pp.17-26, year 2018.

[3] Asad, M.M., Mohammadi, V. and Shirani, M., "Modeling flexibility capabilities of IT-based supply chain, using a grey-based DEMATEL method" Procedia Economics and Finance, 36, pp.220-231, year 2016.

[4] Banerjee, A., "Blockchain technology: supply chain insights from ERP" In Advances in Computers (Vol. 111, pp. 69-98). Elsevier, year 2018.

[5] Bruque-Cámara, S., Moyano-Fuentes, J. and Maqueira-Marín, J.M. "Supply chain integration through community cloud: Effects on operational performance" Journal of Purchasing and Supply Management, 22(2), pp.141-153, year 2016

[6] Chan, C.O., Liu, O. and Szeto, R., "Developing information sharing model using cloud computing and smart devices for SMEs supply chain: A case in fashion retail" International Journal of Information Systems and Supply Chain Management (IJISSCM), 10(3), pp.44-64, year 2017.

[7] Choudhary, S.K. and Jadoun, R.S., "Study about the Types of Information Technology Service for Supply Chain Management" In Proceedings of the World Congress on Engineering and Computer Science (Vol. 2), year 2016.

[8] Emmett, S. and Crocker, B., "The relationship-driven supply chain creating a culture of collaboration throughout the chain" Routledge, year 2016.

[9] Erdil, A. and Erbıyık, H., "The Holistic Perception of Information Technology and The Importance on the Supply Chain Management" International Journal of Research in Business and Social Science (2147-4478), 6(3), pp.1-12, year 2017.

[10] Frank, D., "How one supply chain integrator resolved one investor owned utility's ageing workforce challenges using a scalable solution" Journal of Supply Chain Management, Logistics and Procurement, 1(2), pp.159-171, year 2018.

[11] Fredendall, L.D. and Hill, E., "Basics of supply chain management CRC Press, year 2016.

[12] Giannakis, M. and Louis, M., "A multi-agent based system with big data processing for enhanced supply chain agility" Journal of Enterprise Information Management, 29(5), pp.706-727, year 2016.

[13] Harb, A., Kassem, A., Chartouni, M.A. and Chaaya, L.B., "Effects of warehouse management and engineering system on cost reduction and operations improvement" In 2016 Sixth International Conference on Digital Information Processing and Communications (ICDIPC) (pp. 8-12). IEEE, year 2016.

[14] Hellen, K.A.A.R.I.A. and Patrick, M.W.A.N.G.A.N.G.I., "ROLE OF INFORMATION TECHNOLOGY ON SUPPLY CHAIN PERFORMANCE IN PUBLIC INSTITUTIONS IN KENYA: A CASE OF THE JUDICIARY OF KENYA" International Journal of Logistics and Procurement Management, 1(1), year 2019.

[15] Kafi, F. and Kafi, M., "Information quality in supply chain software" In Handbook of Research on Global Supply Chain Management (pp. 105-126). IGI Global, year 2016.

[16] Katz, N.A., "Successful Supply Chain Vendor Compliance. Routledge, year 2017.

[17] Khan, M.H., Habib, M. and Bakar, E.M.N.E., "SUPPLY CHAIN MANAGEMENT: ITS EVOLUTION-PAST AND PRESENT" In PROCEEDING: 2ND INTERNATIONAL CONFERENCE ON
SOCIAL SCIENCES, HUMANITIES AND TECHNOLOGY (ICSHT 2018) (p. 190), year 2018.

[18] Khan, S.A.R. and Yu, Z., "Key Issues in Logistics and Supply Chain" In Strategic Supply Chain Management (pp. 23-37). Springer, Cham, year 2019 .

[19] Leu, J.D., Krischke, A., Lee, Y.P., Lee, L.J.H. and Huang, Y.W., “An ERP-based Solution for the Supply Chain Planning of Medium-sized Global Manufacturing Company" In 2018 IEEE International Conference on Industrial Engineering and Engineering Management (IEEM) (pp. 1201-1205). IEEE, year 2018.

[20] Liotine, M., Pagano, A.M. and Gadiraju, S.V., "Technology Trends in Logistics and Supply Chain Management" Contemporary Issues in Supply Chain Management and Logistics, p.2, year 2017.

[21] Malhotra, M.K., Mackelprang, A.W. and Jayaram, J., "How inventory consignment programs can improve supply chain performance: a process oriented perspective" Production, 27, year 2017.

[22] Marian, A.I., "Some aspects of Supply Chain Risk Management Global Risks Map and Apple's Approach to Risk Management" Quality-Access to Success, 18(160), year 2017.

[23] Mathrani, S., "Managing Distribution Logistics Using Enterprise Systems" year 2016

[24] Moyano-Fuentes, J., Sacristán-Díaz, M. and Garrido-Vega, P., "Improving supply chain responsiveness through advanced manufacturing technology: the mediating role of internal and external integration" Production Planning \& Control, 27(9), pp.686-697, year 2016.

[25] Neubert, G., Ouzrout, Y. and Bouras, A., "Collaboration and integration through information technologies in supply chains" arXiv preprint arXiv: 1811.01688 , year 2018

[26] Oghazi, P., Fakhrai Rad, F., Karlsson, S. and Haftor, D., "RFID and ERP systems in supply chain management" European Journal of Management and Business Economics, 27(2), pp.171-182, year 2018.

[27] Pinto, A.C.L., Sogamoso, C.A.G. and Bermudez, G.M.T., "ICT supply chain management in Bogota/TIC en gestion de la cadena de suministro Bogotana" Visión electrónica, 10(2), pp.195-203, year 2016.

[28] Ray, S.K., Basak, A., Fatima, K. and Seddiqe, M.I.S., "Study on Supply Chain Management of Industries in FMCG Sector in Bangladesh" Global Journal of Research In Engineering, year 2016.

[29] Saleh, T. and Thoumy, M., "The impact of ERP systems on organizational performance: in Lebanese wholesale engineering companies" In $20187^{\text {th }}$ International Conference on Industrial Technology and Management (ICITM) (pp. 198-204). IEEE, year 2018.

[30] Shahriari, M.R., Pilevari, N. and Gholami, Z., "The effect of information systems on the supply chain sustainability using DEMATEL method" Communications on Advanced Computational Science with Applications, 1, pp.47-56, year 2016.

[31] Simón, F.J.G., Narangajavana, Y. and Llorente, R., "Information systems management in hotel chains" The Routledge Handbook of Hotel Chain Management, p.324, year 2016.

[32] Sindi, S. and Roe, M., "The evolution of supply chains and logistics" In Strategic supply chain management (pp. 7-25). Palgrave Macmillan, Cham, year 2017.

[33] Soosay, C. and Kannusamy, R., "September. Scope for Industry 4.0 in Agri-food Supply Chain" In Hamburg International Conference of Logistics (HICL) 2018 (pp. 37-56). Epubli, year 2018.

[34] Suprapto, W., Tarigan, Z.J.H. and Basana, S.R., "The influence of ERP system to the company performance seen through innovation process, information quality, and information sharing as the intervening variables" In Proceedings of the 2017 International Conference on Education and Multimedia Technology (pp. 87-91). ACM, year 2017.

[35] Szuster, M. and Szymczak, M., "Innovation, knowledge and information management in supply chains" Ekonomia i Zarzadzanie, 8(1), pp.26-36., year 2016.

[36] Tatoglu, E., Bayraktar, E., Golgeci, I., Koh, S.L., Demirbag, M. and Zaim, S., "How do supply chain management and information systems practices influence operational performance? Evidence from emerging country SMEs" International Journal of Logistics Research and Applications, 19(3), pp.181-199, year 2016.

[37] Valverde, R. and Talla, M., "RFID Implementation of Supply Chain: Comparison of Three Case Studies" Available at SSRN 2822142, year 2016.

[38] Williamson, E.A., Harrison, D.K. and Jordan, M., "Information systems development within supply chain management" International Journal of Information Management, 24(5), pp.375-385, year 2004.

[39] Yu, Y., Wang, X., Zhong, R.Y. and Huang, G.Q., "E-commerce logistics in supply chain management: Practice perspective" Procedia Cirp, 52, pp.179-185, year 2016. 
[40] Yu, Y., Wang, X., Zhong, R.Y. and Huang, G.Q., "E-commerce logistics in supply chain management: Implementations and future perspective in furniture industry" Industrial Management \& Data Systems, 117(10), pp.2263-2286, year 2017.

[41] Yusuf, R. and Shehu, A.U., "The review of supply chain management systems and firm performance" International Journal of Management Research and Reviews, 7(2), p.113, year 2017.

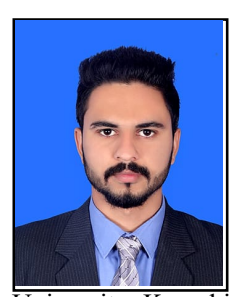

Umair khan citizen of Karachi, Pakistan. Born in December 1992 is an enthusiastic individual dedicating his efforts in the field of supply chain management and Information Technology.

He has done MBA in Supply chain management from Karachi University Business School, Karachi, Pakistan, 2020. Previously completed his BS(Hons) in Computer Science from Sindh Madressatul Islam University, Karachi, Pakistan, 2017.

Mr. Umair khan is working as a DISTRIBUTION MANAGER at Raaziq International in Karachi. Previously was working as team lead in sales at Hashone Creatives. 